\title{
AHybrid Solutions Method for Solving One Dimensional Parabolic Partial Differential Equations
}

\author{
Sunday Babuba* \\ Department of Mathematics, Federal University Dutse, Nigeria
}

Submission: March 19, 2018; Published: July 02, 2018

*Corresponding author: Sunday Babuba, Department of Mathematics, Federal University Dutse, Nigeria, Tel: +2348039282881;

Email: sundaydzupu@yahoo.com

\section{Abstract}

A new continuous numerical method based on polynomials approximation is here proposed for solving the equation arising from heat transfer along a copper rod and a hollow tube subject to initial and boundary conditions. The method results from discretization of the heat equation which leads to the production of a system of algebraic equations. By solving the system of algebraic equations we obtain the problem approximate solutions.

Keywords: Polynomials; Interpolation; Multistep collocation; Parabolic partial differential Equations; Numerical method; One dimensional; Hybrid solutions; Algebraic equations; Heat equation; Heat conduction equation; Interpolation; Collocation; Temperature; Heat flow; Polynomials; Numerical accuracy; Evaporates; Zero; Ethyl alcohol; Initial temperature; Interpolation point.

\section{Introduction}

The development of continuous numerical techniques for solving heat conduction equation in science and engineering subject to initial and boundary conditions is a subject of considerable interest. In this paper, we develop a new numerical method which is based on interpolation and collocation at some point along the coordinates [1-3]. To do this we let $U(x, t)$ represents the temperature at any point in the rod and the tube. Heat is flowing from one end to another under the influence of temperature gradient $\partial U / \partial x$. To make a balance of the rate of heat flow in and out of the media, we consider $R$ for thermal conductivity of the steel, $C$ the heat capacity which we assume constants, and $\rho$ the density and $D$ the thermal diffusivity of alcohol. Heat flow in the rod is given by

$$
-R A \frac{\partial U}{d x}-\left[-R A\left[\frac{\partial U}{d x}+\frac{\partial}{\partial x}\left(\frac{\partial U}{d x}\right) d x\right]\right]=C \rho(A d x) \frac{\partial U}{d t}
$$

Heat flow through the tube is given by

$$
-D B \frac{\partial U}{d x}-\left[-D B\left[\frac{\partial U}{d x}+\frac{\partial}{\partial x}\left(\frac{\partial U}{d x}\right) d x\right]\right]=C \rho(A d x) \frac{\partial U}{d t}
$$

Where $A$ and $B$ are the cross sections of the rod and the tube respectively. Our new method strives to provide solutions to the heat flow eqns. (1.0) and (1.1).

\section{The solution method}

To set up the solution method we select an integer $N$ such that $N>0$. We subdivide the interval $0 \leq x \leq X$ into $N$ equal subintervals with mesh points along the space axis given by $x_{i}=h, \quad i=\frac{1}{\beta}\left(\frac{1}{\beta}\right) N$ where $N=X$. Similarly, we reverse the roles of $x$ nd $t$, we select another integer $M$ such that $M>0$. We also subdivide the interval $0 \leq t \leq T$ into $M$ equal subintervals with mesh points along time coordinate given by $t_{j}=k, j=\frac{1}{\alpha}\left(\frac{1}{\alpha}\right) M$, where $M=T$, and $h, k$ are the mesh sizes along space and time coordinates [4-6]. We seek for the approximate solution $\bar{U}(x, t)$ to $U(x, t)$ of the form

$$
\bar{U}(x, t) \approx \bar{U}_{p-1}(x, t)=\sum_{r=0}^{p-1} a_{r}\left[q_{r}(x, t)+s_{r}(x, t)\right] x \in\left[x_{i}, x_{i+h}\right] t \in\left\lfloor t_{j}, t_{j+k}\right\rfloor
$$

over $h>0, k>0$ mesh sizes, such that $0=x_{0}<\ldots<x_{i}<\ldots<x_{N}, 0=t_{0}<\ldots<t_{j}<\ldots<t_{M}$. We denote $p$ to be the sum of interpolation points along the space and time coordinates respectively. That is $p=g+b$, where $g$ is the number of interpolation points along the space axis, while $b$ is the number of interpolation points along the time coordinate [7]. The bases functions $q_{r}, s_{r} \quad r=0,1, \ldots, p-1$ are the Taylor's and Legendre's polynomials which are known, $a_{r}$ are the constants to be determined. The interpolation values $\bar{U}_{i, j}, \ldots, \bar{U}_{i+h-1, j}$ are assumed to have been determined from previous steps, while the method seeks to obtain $\bar{U}_{i+h, j}$

Applying the above interpolation conditions on eqn. (2.0) we obtain

$$
\begin{aligned}
& \bar{U}_{i+h, j+k}(x, t)=a_{0}\left(q_{0}+s_{0}\right)\left(x_{i+h}, t_{j+k}\right)+a_{1}\left(q_{1}+s_{1}\right)\left(x_{i+h}, t_{j+k}\right)+\ldots+ \\
& a_{p-1}\left(q_{p-1}+s_{p-1}\right)\left(x_{i+h}, t_{j+k}\right)
\end{aligned}
$$


We let $h=-\frac{1}{\beta}\left(\frac{1}{\beta}\right)\left[g-\left(\frac{2 \beta-1}{\beta}\right)\right]$ arbitrarily and $k=0$, then by Cramer's rule, eqn. (2.1) becomes

$$
\begin{aligned}
& W \underline{a}=\underline{F}, \quad \underline{F}=\left(U_{v, j}, U_{v+\frac{1}{\beta},}, \ldots, U_{z, j}\right)^{T}, \\
& \underline{a}=\left(a_{0}, \ldots, a_{p-1}\right)^{T} \\
& W=\left[\begin{array}{ccc}
\left(q_{0}+s_{0}\right)\left(x_{v}, t_{j}\right), & \left(q_{1}+s_{1}\right)\left(x_{v}, t_{j}\right), & , \ldots,\left(q_{p-1}+s_{p-1}\right)\left(x_{v}, t_{j}\right) \\
\left(q_{0}+s_{0}\right)\left(x_{v+\frac{1}{\beta}}, t_{j}\right), & \left(q_{1}+s_{1}\right)\left(x_{v+\frac{1}{\beta}}, t_{j}\right), \ldots,\left(q_{p-1}+s_{p-1}\right)\left(x_{v+\frac{1}{\beta}}, t_{j}\right) \\
\ldots, & \ldots, \ldots, \ldots \\
\left(q_{0}+s_{0}\right)\left(x_{z}, t_{j}\right), & \left(q_{1}+s_{1}\right)\left(x_{z}, t_{j}\right), & , \ldots,\left(q_{p-1}+s_{p-1}\right)\left(x_{z}, t_{j}\right)
\end{array}\right.
\end{aligned}
$$

Where

$z=i+g-\left(\frac{2 \beta-1}{\beta}\right), v=i-\frac{1}{\beta}$ and $W^{-1}$ exist. Hence, from eqn. (2.2), we obtain

$$
\underline{a}=\varpi \underline{F}, \quad \varpi=W^{-1} .
$$

The vector $\underline{a}=\left(a_{0}, \ldots, a_{p-1}\right)^{T}$ is now determined in terms of known parameters in $\varpi \underline{F}$. If $\varpi_{r+1}$ is the $(r+1)^{\text {th }}$ row of $\varpi$, then

$$
a_{r}=\underline{\varpi}_{r+1} \underline{F}
$$

Eqn. (2.4) determines the values of $a_{r}$. Let us take the first and second derivatives of eqn. (2.0) with respect to $x$

$$
\begin{aligned}
& \bar{U}^{\prime}(x, t)=\sum_{r=0}^{p-1}\left[a_{r}\left(q_{r}{ }^{\prime}(x, t)+s_{r}{ }^{\prime}(x, t)\right)\right] \\
& \bar{U}^{\prime \prime}(x, t)=\sum_{r=0}^{p-1}\left[a_{r}\left(q_{r}{ }^{\prime \prime}(x, t)+s_{r}{ }^{\prime \prime}(x, t)\right)\right]
\end{aligned}
$$

Substituting eqn. (2.4) into eqn. (2.5) we obtain

$$
\bar{U}^{\prime \prime}(x, t)=\sum_{r=0}^{p-1}\left[\underline{\varpi}_{r+1} \underline{F}\left(q_{r}^{\prime \prime}(x, t)+s_{r}^{\prime \prime}(x, t)\right)\right]
$$

We reverse the roles of $x$ and $t$ in eqn. (2.1) and we arbitrarily set $k=0\left(\frac{1}{\alpha}\right)\left[b-\left(\frac{\alpha-1}{\alpha}\right)\right], h=0$, again by Cramer's rule,
eqn. (2.1) become

$$
\begin{aligned}
& Y \underline{a}=\underline{E}, \quad \underline{E}=\left(U_{i, \eta-\frac{1}{\alpha}}, U_{i, \eta}, \ldots, U_{i, \gamma}\right)^{T} \\
& \underline{a}=\left(a_{0}, \ldots, a_{p-1}\right)^{T} \\
& \text { and } \\
& Y=\left[\begin{array}{llll}
\left(q_{0}+s_{0}\right)\left(x_{i}, t_{\eta-\frac{1}{\alpha}}\right), & \left.\left(q_{1}+s_{1}\right)\left(x_{i}, t\right), \ldots-\frac{1}{\alpha}\right), & \left(q_{p-1}+s_{p-1}\right)\left(x_{i}, t\right. \\
\left(q_{0}+s_{0}\right)\left(x_{i}, t_{\eta}\right), & \left(q_{1}+s_{1}\right)\left(x_{i}, t_{\eta}\right), & \ldots, & \left(q_{p-1}+s_{p-1}\right)\left(x_{i}, t_{\eta}\right) \\
\ldots, & \ldots, & . . \\
\left(q_{0}+s_{0}\right)\left(x_{i}, t_{\gamma}\right), & \left(q_{1}+s_{1}\right)\left(x_{i}, t_{\gamma}\right), & \ldots, & \left(q_{p-1}+s_{p-1}\right)\left(x_{i}, t_{\gamma}\right)
\end{array}\right]
\end{aligned}
$$

where $\eta=j+\frac{1}{\alpha}, \quad \gamma=j+b-\left(\frac{\alpha-1}{\alpha}\right)$ and $Y^{-1}$ exist.

Hence, from eqn. (2.7) we obtain

$$
\underline{a}=L \underline{E}, \quad L=Y^{-1} .
$$

The vector $\underline{a}=\left(a_{0}, \ldots, a_{p-1}\right)^{T}$ is now determined in terms of known parameters in $L \underline{E}$. If $L_{r+1}$ is the $(r+1)^{h}$ row of $L$, then

$$
a_{r}=\underline{L}_{r+1} \underline{E}
$$

Also, eqn. (2.9) determines the values of $a_{r}$ explicitly.

Taking the first derivatives of eqn. (2.0) with respect to $t$ we obtain

$$
\bar{U}^{\prime}(x, t)=\sum_{r=0}^{p-1}\left[a_{r}\left(q_{r}^{\prime}(x, t)+s_{r}^{\prime}(x, t)\right)\right]
$$

Substituting eqn. (2.9) into eqn. (2.10) we obtain

$$
\bar{U}^{\prime}(x, t)=\sum_{r=0}^{p-1}\left[\underline{L}_{r+1} \underline{E}\left(q_{r}^{\prime}(x, t)+s_{r}^{\prime}(x, t)\right)\right]
$$

But by eqns. (1.0) and (1.1) it is obvious that eqn. (2.11) is equal to eqn. (2.6), therefore,

$$
\begin{aligned}
& \sum_{r=0}^{p-1}\left[\underline{L}_{r+1} \underline{E}\left(q_{r}{ }^{\prime}(x, t)+s_{r}{ }^{\prime}(x, t)\right)\right] \\
& -\sum_{r=0}^{p-1}\left[\underline{\varpi}_{r+1} \underline{F}\left(q_{r}^{\prime \prime}(x, t)+s_{r}{ }^{\prime \prime}(x, t)\right)\right]=0
\end{aligned}
$$

Collocating eqn. (2.12) at $x=x_{i}$ and $t=t_{j}$ produces a new numerical scheme that solves equations (1.0) and (1.1) explicitly.

\section{Numerical examples}

In this section, we will test the numerical accuracy of the new method by using the new scheme to solve two examples. That is, we compute an approximate solutions of eqns. (1.0) and (1.1) at each time level. To achieve this, we truncate the polynomials after second degree and the average is used as the basis function in the computation [8-10]. The resultant scheme is used to solve the following problems.

\section{Example 1}

A hollow tube $20 \mathrm{~cm}$ long is initially filled with air containing $2 \%$ of ethyl alcohol vapors [2]. At the bottom of the tube is a pool of alcohol which evaporates into the stagnant gas above. (Heat transfers to the alcohol from the surroundings to maintain a constant temperature of $30^{\circ} \mathrm{C}$, at which temperature the vapour pressure is $0.1 \mathrm{~atm}$.) At the upper end of the tube, the alcohol vapors dissipate to the outside air, so the concentration is essentially zero. Considering only the effects of molecular diffusion, determine the concentration of alcohol as a function of time and the distance $x$ measured from the top of the tube.

\section{Molecular diffusion follows the law}

$$
\frac{\partial c}{\partial t}=D \frac{\partial^{2} c}{\partial x^{2}}
$$

Where, D is the diffusion coefficient, with units of $\mathrm{cm}^{2}$ / sec. (This is the same as for the ratio $k / p$, which is often termed thermal diffusivity.) For ethyl alcohol, D $=0.119 \mathrm{~cm}^{2} /$ sec at $30{ }^{\circ} \mathrm{C}$, and the vapor pressure is such that 10 volume percent alcohol in air is present at the surface [11-15]. The initial condition is $c(x, 0)=2.0$, and boundary conditions are $c(0, t)=0, c(0, t)=0$. Subdivide the length of the tube into five intervals, so that $\Delta x=4 \mathrm{~cm}$. Using the maximum value permitted for $\Delta t$ yields 


$$
D \frac{\Delta t}{(\Delta x)^{2}}=1, \quad 0.119 \frac{\Delta t}{4^{2}}=1, \Delta t=134 . \$
$$

Taking $\beta=4, \alpha=3$ implies that $v=i-\frac{1}{4}, z=i+\frac{1}{4}$ and $\eta=\gamma=j+\frac{1}{3}$ . For $i=\frac{1}{4}, \frac{1}{2}, \frac{3}{4}, \ldots$, and $j=\frac{1}{3}, \frac{1}{6}, \frac{3}{2}, \ldots$, and by taking two

Table 1: Concentrations of alcohol.

\begin{tabular}{|c|c|c|c|c|c|c|}
\hline$T$ & $x=0$ & $x=4$ & $x=8$ & $x=12$ & $x=16$ & $x=20$ \\
\hline 0 & 0 & 2 & 2 & 2 & 2 & 10 \\
\hline 134.45 & 0 & 1.75 & 2 & 2 & 7 & 10 \\
\hline 268.9 & 0 & 1.56 & 1.97 & 3.5 & 6.94 & 10 \\
\hline 403.35 & 0 & 1.42 & 2.11 & 3.75 & 6.92 & 10 \\
\hline 537.8 & 0 & 1.33 & 2.23 & 3.94 & 6.93 & 10 \\
\hline 672.25 & 0 & 1.28 & 1.67 & 4.1 & & 10 \\
\hline
\end{tabular}

\section{Example 2}

Solve for the temperature in a copper rod $1.2 \mathrm{~cm}$ long, with the outer curved surface insulated so that heat flows in on one direction [21-24]. If the initial temperature $\left({ }^{\circ} C\right)$ within the rod are given by

$$
U=100 x \text { for } 0 \leq x \leq 0.6, \quad U=100(1.2-x), \text { for } 0.6 \leq x \leq 1.2
$$

Find the temperature as a function of $x$ and $t$ if both faces are maintained at $0^{\circ} \mathrm{C}$. For copper, $k=0.3, \quad p=0.433$. We use $\Delta x=0.0 \mathrm{~m}$, we then find $\Delta t$ by the relation interpolation points along space coordinate and one interpolation point along time coordinate implies that $g=2, b=1, \Rightarrow p=3$ , and this simply means that $h=-\frac{1}{4}, 0, \frac{1}{4}$ and $k=0, \frac{1}{2}$, then the calculated concentration of alcohol is as shown in Table 1 [15-20].
Table 2: Calculated temperatures.

\begin{tabular}{|c|c|c|c|c|c|c|c|}
\hline$t$ & $x=0$ & $x=0.2$ & $x=0.4$ & $x=0.6$ & $x=0.8$ & $x=1.00$ & $x=1.20$ \\
\hline 0 & 0 & 20 & 40 & 60 & 40 & 20 & 0 \\
\hline 0.01 & 0 & 20 & 40 & 55 & 40 & 20 & 0 \\
\hline 0.02 & 0 & 20 & 39.38 & 51.25 & 39.38 & 20 & 0 \\
\hline 0.03 & 0 & 19.92 & 38.44 & 48.28 & 38.44 & 19.92 & 0 \\
\hline 0.04 & 0 & 19.75 & 37.36 & 45.82 & 37.36 & 19.75 & 0 \\
\hline 0.05 & 0 & 19.48 & 36.22 & $43.71 \mathrm{~s}$ & 36.22 & 19.48 & 0 \\
\hline
\end{tabular}

\section{References}

1. Adam A, David R (2002) One dimensional heat equation.

2. Awoyemi DO (2002) An Algorithmic collocation approach for direct solution of special fourth- order initial value problems of ordinary differential equations. Journal of the Nigerian Association of Mathematical Physics 6: 271-284.

3. Awoyemi DO (2003) A P- stable linear multistep method for solving general third order Ordinary differential equations. Int J Computer Math 80(8): 987-993.

4. Bao W, Jaksch P, Markowich PA (2003) Numerical solution of the GrossPitaevskii equation for Bose-Einstein condensation. J Compt Phys 187(1): 18-342.

5. Benner P, Mena H (2004) BDF methods for large scale differential Riccati equations in proc. of mathematical theory of network and systems. MTNS.

6. Bensoussan A, Da Prato G, Delfour M, Mitter S (2007) Representation and control of infinite dimensional systems, ( $2^{\text {nd }}$ edition $)$, Springer, UK.

$$
\frac{k \Delta t}{p(\Delta x)^{2}}=\frac{1}{4}, \Delta t=0.0
$$
. For $i=\frac{1}{4}, \frac{1}{2}, \frac{3}{4}, \ldots$, and $j=\frac{1}{8}, \frac{1}{4}, \frac{3}{8}, \ldots$, and by taking two interpolation points along space coordinate and one interpolation point along time coordinate implies that $g=2, b=1$, and $p=3$, this simply gives $h=-\frac{1}{4}, 0, \frac{1}{4}$ and $k=0, \frac{1}{8}$, then the calculated temperatures are as shown in Table 2 [25-27].
Taking $\beta=4, \alpha=\mathbf{2}$ implies that $v=i-\frac{1}{4}, z=i+\frac{1}{4}$ and $\eta=\gamma=j+\frac{1}{8}$

7. Biazar J, Ebrahimi H (2005) An approximation to the solution of hyperbolic equation By a domain decomposition method and comparison with characteristics Methods. Appl Math and Comput 163(2): 633-648.

8. Brown PLT (1979) A transient heat conduction problem. AICHE Journal 16: 207-215.

9. Chawla MM, Katti CP (1979) Finite difference methods for two-point boundary value problems involving high-order differential equations. BIT 19(1): 27-39.

10. Cook RD (1974) Concepts and Application of Finite Element Analysis: NY: Wiley Eastern Limited, USA.

11. Crandall SH (1955) An optimum implicit recurrence formula for the heat conduction equation. JACM 13: 318-327.

12. Crane RL, Klopfenstein RW (1965) A predictor-corrector algorithm with increased range of absolute stability. JACM 12: 227-237.

13. Crank J, Nicolson P (1947) A practical method for numerical evaluation of solutions of partial differential equations of heat conduction type. Proc Camb Phil Soc 6: 32-50. 
14. Dahlquist G, Bjorck A (1974) Numerical methods. NY: Prentice Hall.

15. Dehghan M (2003) Numerical solution of a parabolic equation with non-local boundary specification. Appl Math Comput 145(1): 185-194.

16. Dieci L (1992) Numerical analysis. SIAM Journal 29(3): 781-815.

17. Douglas J (1961) A Survey of Numerical Methods for Parabolic Differential Equations in advances in computer II. Academic press, USA.

18. D' Yakonov, Ye G (1963) On the application of disintegrating difference operators. Z Vycist Mat I Mat Fiz 3: 385-395.

19. Eyaya BE (2010) Computation of the matrix exponential with application to linear parabolic PDEs.

20. Fox L (1962) Numerical Solution of Ordinary and Partial Differential Equation. New York: Pergamon, USA.

21. Penzl T (2000) Matrix analysis. SIAM J 21: 1401-1418.
22. Pierre J (2008) Numerical solution of the dirichlet problem for elliptic parabolic Equations. SIAM J Soc Indust Appl Math 6(3): 458-466.

23. Richard LB, Albert C (1981) Numerical analysis. Berlin: Prindle, Weber and Schmidt, inc, USA.

24. Richard L, Burden J, Douglas F (2001) Numerical analysis, ( $7^{\text {th }}$ edn), Berlin: Thomson Learning Academic Resource Center, USA.

25. Saumaya B, Neela N, Amiya YY (2012) Semi discrete Galerkin method for Equations of Motion arising in Kelvin-Voitght model of viscoelastic fluid flow. Journal of Pure and Applied Science 3(2\&3): 321- 343.

26. Yildiz B, Subasi M (2001) On the optimal control problem for linear Schrodinger equation. Appl Math and Comput121: 373-381.

27. Zheyin HR, Qiang X (2012) An approximation of incompressible miscible displacement in porous media by mixed finite elements and symmetric finite volume element method of characteristics. Applied Mathematics and Computation, 143: 654 - 672.

\section{Your next submission with Juniper Publishers will reach you the below assets}

- Quality Editorial service

- Swift Peer Review

- Reprints availability

- E-prints Service

- Manuscript Podcast for convenient understanding

- Global attainment for your research

- Manuscript accessibility in different formats

( Pdf, E-pub, Full Text, Audio)

- Unceasing customer service

Track the below URL for one-step submission https://juniperpublishers.com/online-submission.php 